\title{
Evaluating the Mobile Web Accessibility of electronic text for print impaired people in Higher Education
}

\author{
Neil Rogers \\ University of Southampton \\ University Road \\ Southampton SO17 1BJ \\ (Contact through Professor Wald) \\ nrer1g14@ecs.soton.ac.uk
}

\author{
Professor Mike Wald \\ University of Southampton \\ University Road \\ Southampton SO17 1BJ \\ +44 (0)238059 3667 \\ mw@ecs.soton.ac.uk
}

\author{
E.A. Draffan \\ University of Southampton \\ University Road \\ Southampton SO17 1BJ \\ +44 (0)23 80597246 \\ ead@ecs.soton.ac.uk
}

\begin{abstract}
The aim of this extended abstract is to demonstrate a framework that provides a novel solution for evaluating the mobile web accessibility of electronic text for print impaired people in Higher Education (HE). The current framework explores over 500 device settings. Furthermore, the scope of this research is outlined alongside two research questions. The paper then concludes by suggesting the potential impact this research could have on existing standards, the public availability of metadata and guidelines, and the automatic generation of personalised eTexts as per user needs.
\end{abstract}

\section{CCS Concepts}

- Information systems $\rightarrow$ Combination, fusion and federated search $\bullet$ Human-centred computing $\rightarrow$ User centred design • Human-centred computing $\rightarrow$ Smartphones $\bullet$ Human-centred computing $\rightarrow$ E-book readers $\bullet$ Human-centred computing $\rightarrow$ Tablet computers - Social and professional topics $\rightarrow$ Assistive technologies.

\section{Keywords}

Navigation; e-Text; e-Pub3; AZW; Higher Education; print impairment; device settings; user agent settings; relearning.

\section{INTRODUCTION}

The research presented in this paper currently focuses on HE but could also be repurposed across a broader age range, from the elderly through to K12. In the UK, the K12 category relates to ages between Key Stage 1 (KS1) - 5 to 7 years of age, and A' Level 16 years and older [1]. Since this paper is focused on HE, two related research questions are stated - $R Q 1$ and $R Q 2$. In so doing, relevant literature is respectively considered for both. $R Q 1$ : How does mobile web accessibility need to be evaluated in the context of Higher Education Institute (HEI) library provision of electronic text for users with print impairments? In order to achieve this the process behind the provision of electronic text needs to be understood. Academic staff or students searching for and finding online digital academic text is integral to what institute libraries refer to as a 'Federated Search Tool', within the institutional domain; or the 'Discovery Layer' when in the public domain [7]. McNaught et al, in 2010, provide the eBook Access Bridge Model

\footnotetext{
SAMPLE: Permission to make digital or hard copies of part or all of this work for personal or classroom use is granted without fee provided that copies are not made or distributed for profit or commercial advantage and that copies bear this notice and the full citation on the first page. Copyrights for third-party components of this work must be honoured. For all other uses, contact the Owner/Author.

Copyright is held by the owner/author(s).

$W 4 A^{\prime} 16$, April 11-13, 2016, Montreal, Canada.

Copyright 2016 ACM 978-1-4503-4138-7/16/04.

DOI: http://dx.doi.org/10.1145/2899475.2899504
}

where users with disabilities traverse an 'inclusion gap' - doubling as a research gap - from a digital file format through to 'constructed knowledge' [4]. McNaught et al also state that the accessibility of electronic texts (eTexts) for the 'average' institutional user is unexpectedly multi-staged, and that he or she is required to navigate different institutional 'systems' [4]. RQ2: What categories support a framework for the mobile accessibility settings that meet the needs of users with print impairments interacting with electronic text in HEI libraries? Print disabilities are defined by Kerscher [3] as '[a] person who cannot effectively read print because of a visual, physical, perceptual, developmental, cognitive, or learning disability'. This paper concentrates on three aspects of this definition: dyslexia; dexterity; and blindness or visual impairment. Shneiderman [6], when considering Universal Usability, states that with an increase in the complex nature of 'computing services' the success of their use is brought into question. Alongside this, Nielsen [5] considers the need for a user to be able to recall how to use a system with ease, referring to this as 'Memorability'. Recall of complex menu structures may impact a user who has dyslexia. Jeffries et al [2] link 'working memory' with Dyslexia. Zhong et al [9], aptly demonstrate the need for addressing 'hand tremor' when disambiguating between on screen Operating System (OS) menu items. Yesilada et al [8] identify the barriers common to mobile and disabled web users by highlighting the similarities between people with visual impairments and mobile users operating small screen devices. Moreover, this demonstrates that accessibility affects every user.

\section{METHODOLOGY}

In line with the research undertaken by McNaught et al, a novel solution was provided in the form of an Accessibility Evaluation Framework shown in Figure 1.

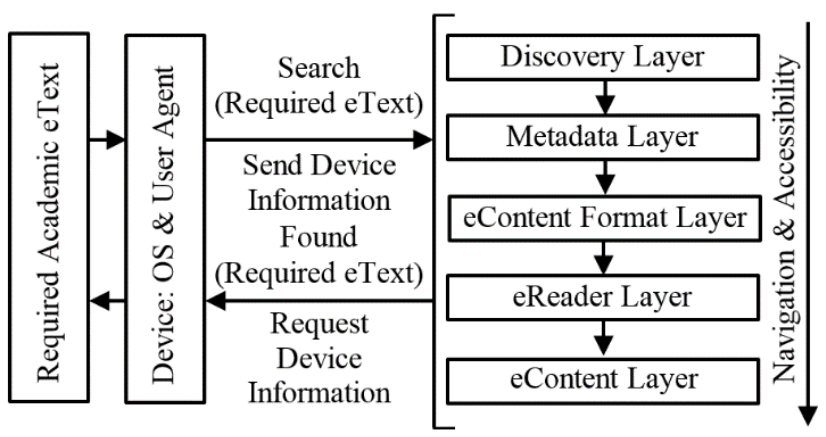

Figure 1: Accessibility Evaluation Framework

The far left of this framework indicates the required academic eTexts. These might take the form of a journal paper, academic literature, or a previous exam paper for revision purposes. Using the device through the OS and User Agent (UA) settings, a user is 
able to search for and find the required eText. The UA, in this context, refers to: applications such as Adobe Acrobat Reader; and mainstream browsers. Notably, the means to enable a particular type of search is indicated by the Discovery Layer. In this instance the framework is focused on HEI libraries but could, however, be repurposed towards educational publishers or educators. This layer is driven by metadata, examples of which might include the name of the author or book title. In most cases the user is then presented with the option to download or transfer eContent formats, such as a PDF or ePub, to the cloud. Dedicated eReaders such as the Kindle Paper White or multifunctional devices such as smartphones or tablets can then be used to navigate through the electronic content. So for example, the user might need to alter the granularity of navigation through chapters, headings, paragraphs, sentences and words. The user may even need to go as far as isolating single characters. Since the settings for both the OS and the User Agent menus aid navigation, the following mappings were identified - see Figure 2.

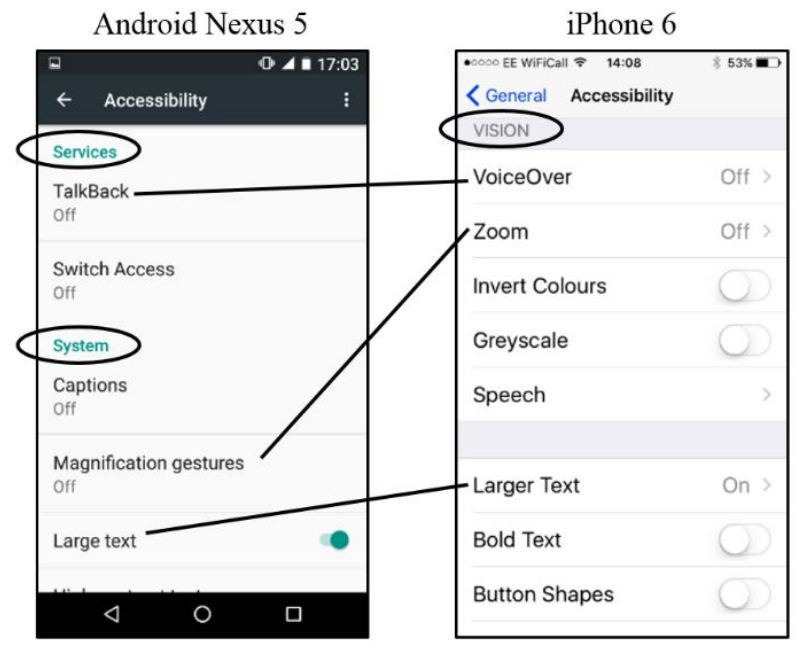

Figure 2: Example Mappings of OS Menu Settings

The Android Nexus 5 screenshot provides two examples of manufacturer categories (indicated by ellipses) 'Services' and 'System'; whereas the iPhone 6 screenshot offers one manufacturer category 'Vision'. The direct mapping across device settings may allow potential niche device settings to be identified, alongside a possible means to measure those that are essential for accessibility.

\section{RESULTS (Initial findings)}

In total, 233 smartphone screen shots were analysed for the current framework. 49 were taken from an Android Nexus 5 running Marshmallow; and 184 were taken from an iPhone 6 running iOS 9.1. This has resulted in over 500 settings, between two smartphone devices, and 40 mappings. The analysis is currently ongoing across mainstream mobile devices, applications and browsers.

\section{DISCUSSION}

Based on the results (initial findings), it appears that manufacturers devise their own categories, because the Android screen reader TalkBack is categorised under 'Services'; but the iPhone screen reader VoiceOver is categorised under 'Vision'. If a device, however, is upgraded, updated or changed then the menu settings could be altered. We therefore need to categorise the accessibility settings in such a way that they are device agnostic and unaffected by device or software updates. The accessibility settings will also need to remain meaningful, useful and relearned easily if required.
This can be achieved through mobile functional categories. So for example, because font or text size adjustment can be mapped across multiple devices, applications and browsers it suggests this is an essential setting. There is, however, a caveat some devices may have essential settings that cannot be mapped as yet. Furthermore, the mappings were then assessed for their fit to the framework and the relevance of device, application and browser settings to eReading in Higher Education.

\section{CONCLUSION}

This research has the potential to impact how evaluating the mobile web accessibility of electronic text for print impaired people in Higher Education (HE) can be achieved. Furthermore, it may help clarify existing standards, make metadata and guidelines publicly available and automatically generate personalised eTexts as per user needs.

\subsection{Future Work}

Further analysis of the framework is to be undertaken. In addition to this, a prototype mobile application will be developed in preparation for heuristic evaluation.

\section{ACKNOWLEDGMENTS}

This research is funded by an EPSRC Case Award with Microlink as the industrial partner.

\section{REFERENCES}

[1] DEPARTMENT FOR EDUCATION., 2015. National curriculum in England: framework for key stages 1 to 4 Department for Education, London. http://goo.gl/1G0sV7

[2] JEFFRIES, S. and EVERATT, J., 2004. Working memory: Its role in dyslexia and other specific learning difficulties. Dyslexia 10, 3 (//), 196-214. DOI= http://dx.doi.org/10.1002/dys.278.

[3] KERSCHER, G., 2015. The definition of "print disabled"? Reading Rights Coalition, United States of America. http://goo.gl/JItGm1

[4] MCNAUGHT, A., EVANS, S., and BALL, S., 2010. E-Books and Inclusion: Dream Come True or Nightmare Unending? In Computers Helping People with Special Needs, K. MIESENBERGER, J. KLAUS, W. ZAGLER and A. KARSHMER Eds. Springer Berlin Heidelberg, 74-77. DOI= http://dx.doi.org/10.1007/978-3-642-14097-6_13.

[5] NIELSEN, J., 1993. Usability Engineering. Morgan Kaufmann: An Imprint of Elsevier, San Diego. http://goo.gl/IjGPoB

[6] SHNEIDERMAN, B., 2000. Universal Usability. Commun. $A C M$ 43, 5, 84-91. DOI= http://dx.doi.org/10.1145/332833.332843.

[7] YANG, S.Q. and WAGNER, K., 2010. Evaluating and comparing discovery tools: how close are we towards next generation catalog? Library Hi Tech 28, 4, 690-709. DOI= http://dx.doi.org/doi:10.1108/07378831011096312.

[8] YESILADA, Y., BRAJNIK, G., and HARPER, S., 2011. Barriers common to mobile and disabled web users. Interacting with Computers 23, $5(9 / /), 525-542$. DOI= http://dx.doi.org/http://dx.doi.org/10.1016/j.intcom.2011.05.005.

[9] ZHONG, Y., WEBER, A., BURKHARDT, C., WEAVER, P., and BIGHAM, J.P., 2015. Enhancing Android Accessibility for Users with Hand Tremor by Reducing Fine Pointing and Steady Tapping. In Proceedings of the W4A (Florence, Italy, May 1820, 2015 2015), 1-9. DOI=

http://dx.doi.org/http://dx.doi.org/10.1145/2745555.2747277. 